\title{
ANALISA KOROSI MATERIAL PADA PROSES HYDROTREATING POLY FATTY ACID DESTILLATE
}

\author{
Mukhlis $^{1 *}$, Bambang Widyanto ${ }^{2}$ \\ ${ }^{1}$ Teknik Pengelasan, Politeknik Perkapalan Negeri Surabaya \\ email: mukhlis.ppns15@gmail.com \\ ${ }^{2}$ Teknik Material, Institut Teknologi Bandung
}

diterima tanggal : 20 Februari 2018 disetujui tanggal : 10 Mei 2018

Abstrak

Kajian ini bermaksud untuk menentukan material yang tahan korosi untuk peralatan proses hydrotreating Poly Fatty Acid Distillate (PFAD). Pengujian korosi ini dilakukan terhadap baja tahan karat feritik dan austenik dengan metode imersi dalam autoclave. Hasil pengujiaa ini untuk melengkapi pengujian yang sama yang telah dilakukan pada material baja karbon, baja krom-moly dan baja tahan karat martensitic. Autoclave dioperasikan pada tekanan sekitar $15,7 \div 29,42$ bar, temperatur $140 \div 300^{\circ} \mathrm{C}$, kadar TAN $45 \div 169,19 \mathrm{mg} \mathrm{KOH/ml} \mathrm{per} \mathrm{sampel} \mathrm{minyak} \mathrm{dan} \mathrm{kadar} \mathrm{air} 0 \div 17 \%$ volume. Kemudian, karakterisasi material dan media digunakan FTIR-GCMS, mikroskop cahaya, scanning electron microscope, dan uji kehilangan berat material. Dari hasil FTIR-GCMS diketahui adanya agen korosi berupa asam karboksilat, namun belum dapat dipastikan secara signifikan bahwa asam tersebut adalah asam naftanik. Sementara itu, hasil pengamatan dengan mikroskop cahaya dan SEM terlihat profil permukaan material yang terkorosi. Ketika uji imersi dilakukan pada temperatur $300^{\circ} \mathrm{C}$, tekanan 29,42 s/d 34,3, kadar air 17\% volume and nilai TAN 169,19 mg KOH / gr sampel minyak, terlihat bahwa temperature dan nilai TAN berpengaruh signifikan terhadap laju korosi. Setelah membandingkan hasil penelitian ini dan sebelumnya, baja tahan karat austenik memilik ketahanan korosi yang baik pada proses hydro-treating media yang mengandung Poly Fatty Acid Distillate (PFAD).

Kata kunci: Hydro-treating, PFAD, korosi, baja tahan karat.

\begin{abstract}
This study has objective to find corrosion resistant material for hydro-treating process of Poly Fatty Acid Distillate (PFAD). Corrosion testing on this study was conducted on ferritic stainless steel and austenitic stainless steel by immersion testing in autoclave. Results of this study will outfit the prior study which was done on carbon steel, chrome-moly steel, and martensitic stainless steel. Autoclave is operated at range of pressure about $15,7 \div 29,42$ bar, temperature $140 \div 300^{\circ} \mathrm{C}$, feed's TAN value $45 \div$ $169,19 \mathrm{mg} \mathrm{KOH} / \mathrm{ml}$ of oil sample and water content of feed about $0 \div 17 \%$ volume. Characterization of material and feed will performed by FTIR-GCMS, optical microscope, scanning electron microscope, and weight loss test. It was observed by FTIR-GCMS that corrosion agent is carboxylic acid, but it was not well understood if subjected acid is naphthenic acid. While, through optical microscopy and SEM it was found that uniform corrosion was occurred. When immersion testing was performed at $300^{\circ} \mathrm{C}$, 29,42 s/d 34,3 bar, 17\% volume of water and TAN value 169,19 mg KOH / gr sample, it was observed significant effect on corrosion rate which show that temperature, and TAN value have significant effect on corrosion rate. Comparing result of corrosion study between material from carbon steel, chromemoly steel, martensitic stainless steel, ferritic stainless steel and austenitic stainless steel, it was found that austenitic stainless steel has good corrosion resistant in hydro-treating process of Poly Fatty Acid Distillate (PFAD).
\end{abstract}

Keywords: hydro-treating, PFAD, corrosion, stainless steel. 


\section{PENDAHULUAN}

Harga minyak dunia selalu bergejolak. Hal ini dapat mempengaruhi stabilitas ekonomi dan politik, terutama bagi Negara - Negara pengimpor minyak mentah seperti Indonesia. Untuk itu perlu upaya untuk memaksimalkan pemanfaatan sumber energy alternative yang melimpah dan ramah lingkungan untuk diolah menjadi biodiesel. Sebagai Negara penghasil kelapa sawit, Indonesia memiliki bahan baku biodiesel yang melimpah, diantaranya poly fatty acid destilate. PFAD merupakan produk sampingan dalam proses produksi minyak nabati yang dikonsumsi manusia[12].

Biodiesel tersusun dari monoalkil ester fatty acid yang dapat disintesis dari minyak tumbuhan, hewan, maupunalga [7,13]. Beberapa kelebihan dari penggunaan bahan bakar biodiesel antara lain biodegradable (dapat terurai oleh lingkungan), tidak beracun, serta dapat menggantikan bahan bakar solar diesel dalam banyak aplikasi seperti boiler dan mesin pembakaran internal tanpa modifikasi pada mesin atau kehilangan unjuk kerja. Bahkan dengan pemakaian biodiesel mampu mereduksi emisi hidrokarbon (HC), karbon monoksida (CO), dan particulate matter (PM) serta dapat mengeliminasi emisi sulfat dan karbon dioksida (CO2) [1]. Selain itu, biodiesel memiliki sifat yang hampir sama seperti halnya bahan bakar diesel konvensional dalam berbagai hal diantaranya viskositas, flash point, cetane number (TAN), dll [8].

Untuk menghasilkan biodiesel dari minyak nabati, metode yang umum dikenal yaitu metode trans-esterifikasi. Kelemahan proses ini adalah produk biodiesel mudah teroksidasi dalam penyimpanan.

Salah satu alternative metode produksi biodiesel yakni metode hydrotreating [5]. Hydrotreating merupakan salah satu proses yang sudah umum dilakukan dalam proses distilasi minyak mentah menjadi solar. Proses ini berlangsung pada tekanan dan temperature tinggi. Bio-solar dari hasil hydrotreating minyak nabati memiliki sifat yang sangat mirip dengan solar konvensional, daya tahan simpan yang lebih baik.

Disisi lain, bahan baku dari minyak nabati atau minyak kualitas rendah memiliki nilai TAN yang melampaui syarat minimum nilai TAN yang aman terhadap permasalahan korosi pada peralatan hydrotreating $[3,6]$. Korosi material akan terjadi ketika terekspose dalam proses hydrotreating dengan media minyak nabati $[2,4,9,10,11,14]$.

Dari penelitian ini diharapkan dapat mengetahui pengaruh parameter nilai TAN dan temperature terhadap ketahanan korosi material, mengetahui jenis korosi dan mengetahui material yang memiliki ketahanan yang lebih baik terhadap korosi dalam kondisi hydrotreating process.

\section{METODEPENELITIAN}

2.1 Material uji dan Bahan

Dalam penelitian ini, material uji yang digunakan adalah baja tahan karat :

- Grade 316 / A240 TP316, baja tahan karat tipe austenik

- Grade 430 / A240 TP430, baja tahan karat tipe feritik

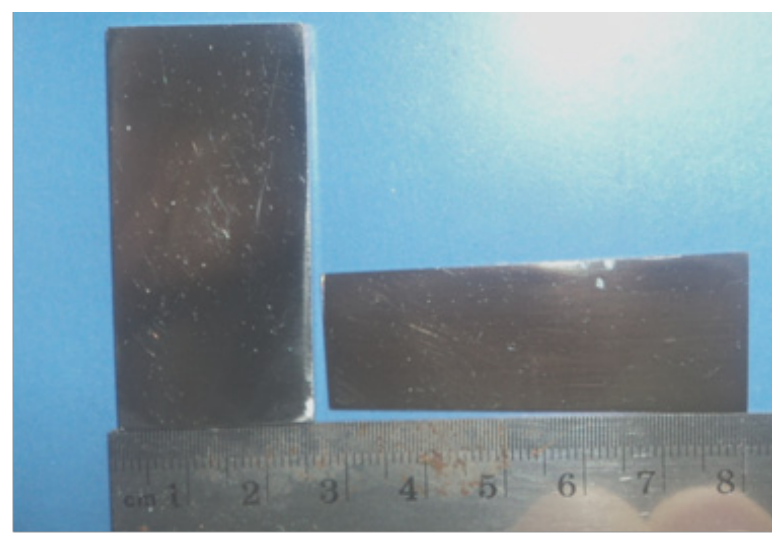

Gambar 2.1 Kupon uji Immerssion

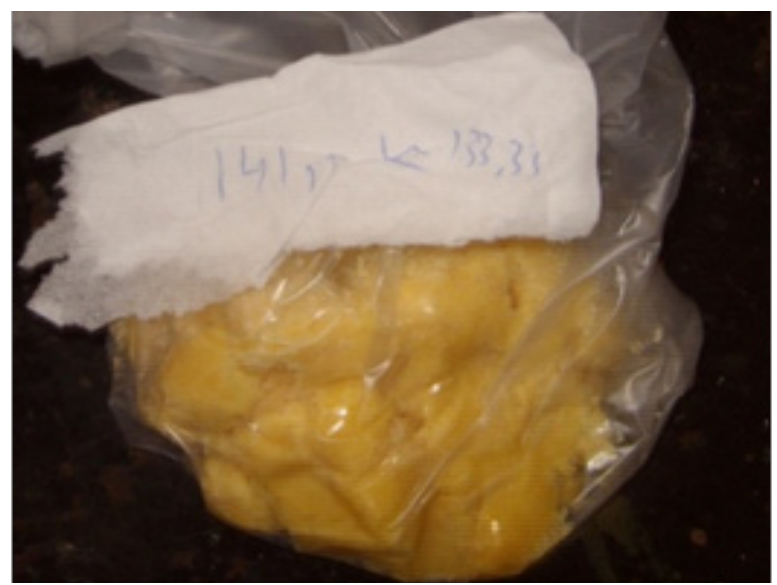

Gambar 2.2 PFAD 
Media uji Pada Gambar 2.1 merupakan kombinasi antara :

- PFAD.

- Minyak goreng

- Aquades

Bahan pendukung pada Gambar 2.2 antara lain :

- Aseton

- Alkohol

- Kertas amplas

\subsection{Peralatan}

Alat utama yang digunakan dalam penelitian ini adalah autoclave.

Pada autoclave ini dilengkapi dengan heater yang mampu mencapai temperature $600^{\circ} \mathrm{C}$. kemudian, Untuk mengetahui kondisi operasinya, maka dilengkapi dengan indicator temperature dan tekanan.

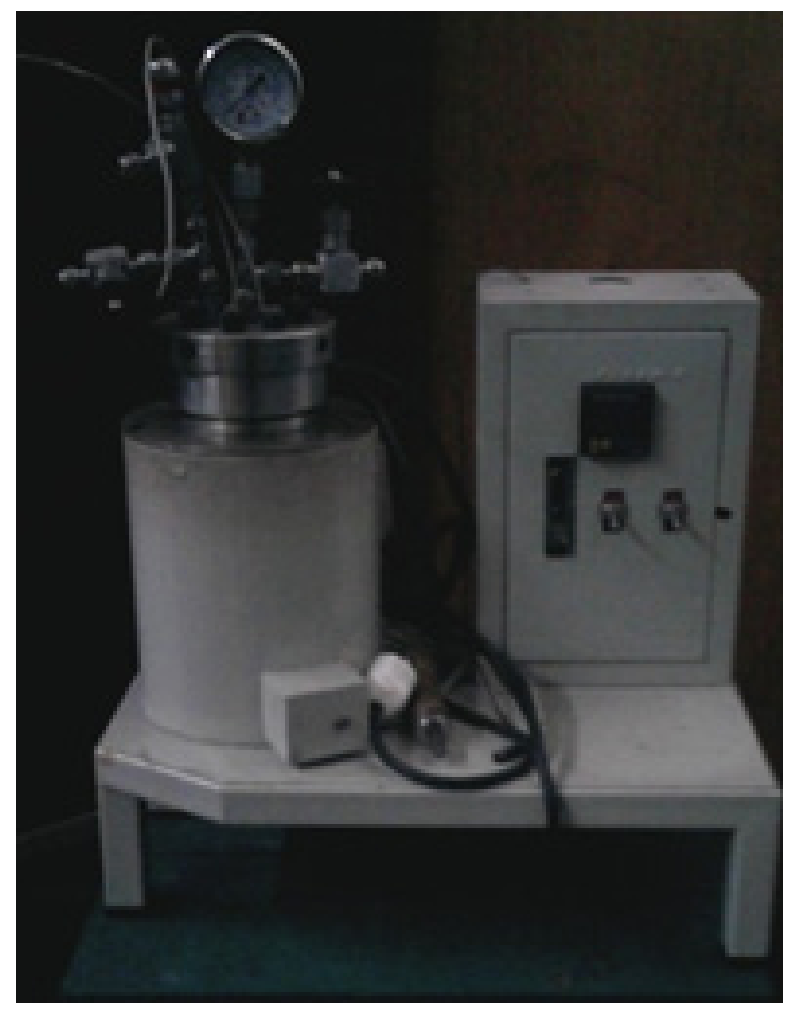

Gambar 2.3 Autoclave mini

Sementaraitu, alat pendukung yang digunakan adalah :

- Alat untuk mempersiapkan specimen uji seperti; alat potong accutom merk struers, mesin amplas, hair drier, kaliper, timbangan presisi tinggi,

- Alat untuk mempersiapkan media hydrotreating seperti; gelas ukur, pipet, oven.

- Alat untuk mengkarakterisasi material; mikroskop optis, SEM.

- Alat untuk mengakarakterisasi media hydrotreating seperti; FTIR merk Shimadzu, GCMSmerk shimadzu.

Setelah perangkat dan bahan tersebut tersedia, percobaan dilakukan dengan langkah langkah sbb:

1. Purging autoclave dengan nitrogen, untuk menghilangkan agen korosi lain dalam atmosfir autoclave.

2. Immersion testing pada dengan kondisi tekanan 22,6bar, kadar air 17\%, temperature kerja $230^{\circ} \mathrm{C}-300^{\circ} \mathrm{C}$ dengan variasi TAN masing masing adalah45,32, 106,45, 118,89 dan 169,19 mg KOH per gr.sampel PFAD

3. Karakterisasi produk korosi dengan FTIRGCMS, karakterisasi material dengan Optical microscope, SEM dan weigth loss test.

Penggunaan FTIR-GCMS diharapkan terdeteksi keberadaan asam naftanik, agen korosi yang biasanya terdapat dalam media. Pengamatan visual dengan Optical microscope dan SEM digunakan untuk melihat profil yang terkorosi. Dan, weight loss testing akan menggambarkan ketahanan korosi material uji.

\section{HASIL DAN PEMBAHASAN}

\subsection{Hasil FTIR dan GCMS}

Dalam penelitian ini, korosi diindikasikan oleh adanya asam naftanik dalam media. Asam naftanik merupakan salah satu gugusan asam karboksilat, keberadanya akan terdeteksi dari hasil FTIR-GCMS. Absorpsi IR asam karboksilat terdiri dari empat kategori yaitu O-H strech (3400-2400 $\mathrm{Cm}-1), \mathrm{C}=\mathrm{O}$ strech $(1730-1700 \mathrm{Cm}-1), \mathrm{O}-\mathrm{H}$ bend (1440-1400 Cm-1), dan C-O stretch (1320 - 1210 Cm-1).

Berdasarkan hasil FTIR berikut; 


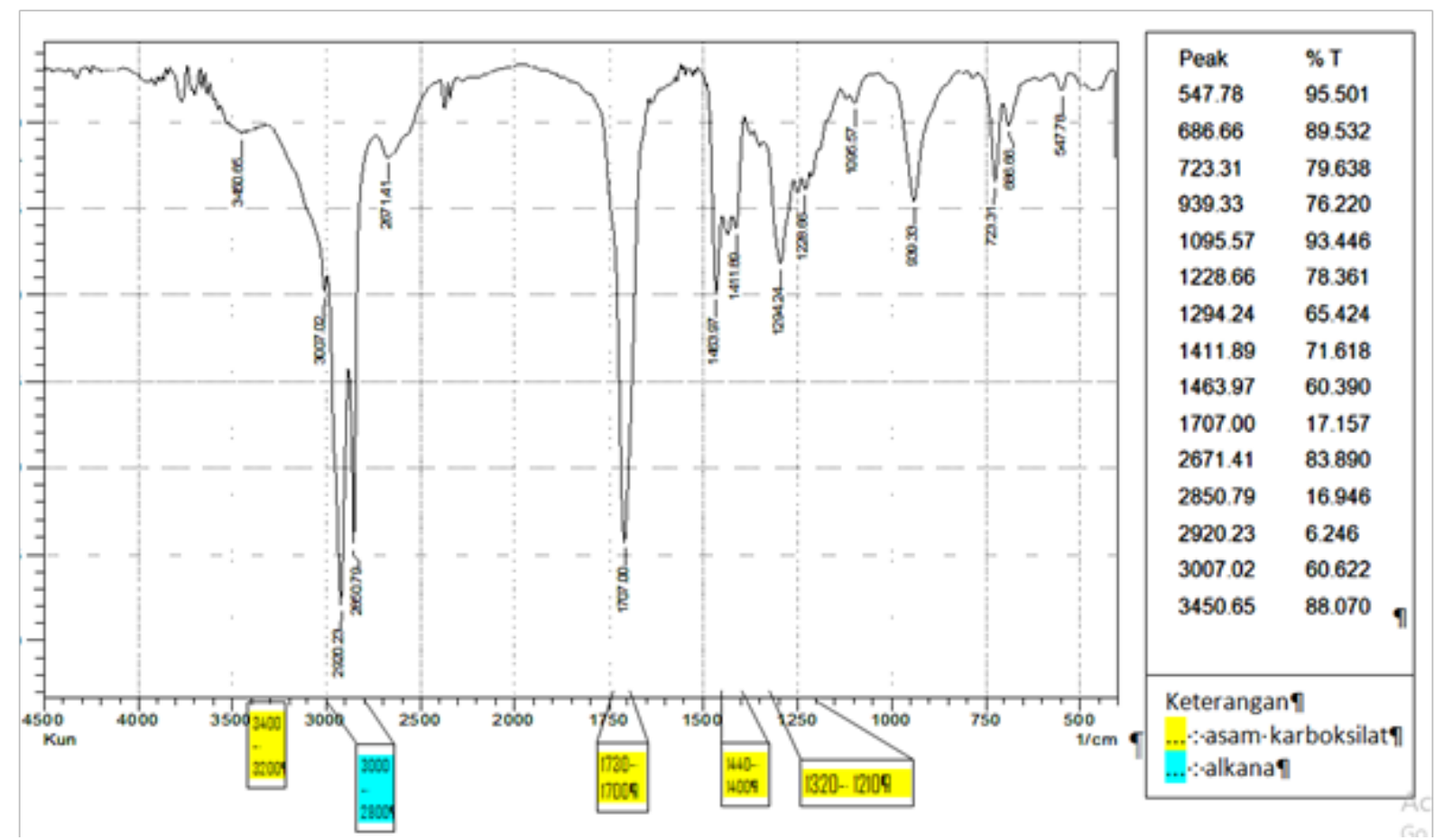

Gambar 3.1 hasil FTIR PFAD

Gugus fungsi yang terdapat pada PFAD adalah Alkana C-H stretch dan asam karboksilat $\mathrm{C}=\mathrm{O}$ stretch. Hal ini mengarahkan dugaan bahwa korosi yang terjadi adalah korosi yang disebabkan oleh asam karboksilat. Dugaan ini juga diperkuat oleh berkurangnya jumlah / kadar $\mathrm{C}=\mathrm{O}$ strech (1730-1700 Cm-1) dalam media setelah immersion testing

Setelah memastikan keberadaan asam karboksilat dengan FTIR, langkah selanjutnya adalah mencari turunan asam karboksilat yang berupa asam naftanik, yang mana dalam penelitian ini dilakukan dengan analisa GCMS. Dari hasil GCMS tersebut tidak dijumpai adanya turunan asam karboksilat yang berupa asam naftanik, hal ini diduga disebabkan oleh kelemahan / keterbatasan GCMS untuk mendeteksi senyawa yang terlalu khas.

\subsection{Hasil Optical Microscope dan SEM}

Setelah dilakukan Immersion testing dan pembersihan permukaan material uji dari minyak dan produk korosi, ada dua metode observasi visual yang dilakukan untuk melihat indikasi adanya proses korosi pada permukaan logam yaitu pengamatan dengan mikroskop optik dan pengamatan dengan mikroskop elektron.

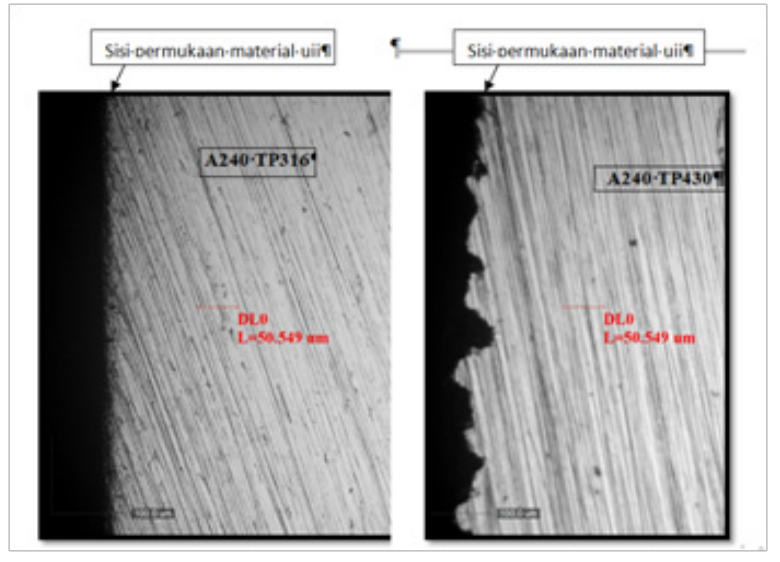

Gambar 3.2 Potongan melintang A240 TP316 dan A240 TP430 hasil pengamatan dengan mikroskop optik setelah Immersion testing pada Tekanan 29,42 bar, T $300^{\circ} \mathrm{C}$, media PFAD, durasi 24 jam

Dalam Gambar 3.3, terlihat permukaan kedua material uji sebelum immersion testing memiliki kekasaran permukaan yang relatif sama oleh karena diamplas hingga grit amplas yang sama, 800 grit. Namun kekasaran permukaan kedua material tersebut terlihat berbeda setelah immersion testing yang mengindikasi bahwa kedua material uji tersebut telah mengalami korosi dengan tingkat laju korosi yang berbeda. A240 TP430, sebelah kiri bawah, menunjukan permukaan yang 
lebih kasar dari permukaan A240 TP316, gambar sebelah kanan bawah, yang mengindikasikan bahwa kedua material mengalami korosi dimana A240 TP430 mengalami laju korosi yang relatif lebih tinggi daripada A240 TP316.

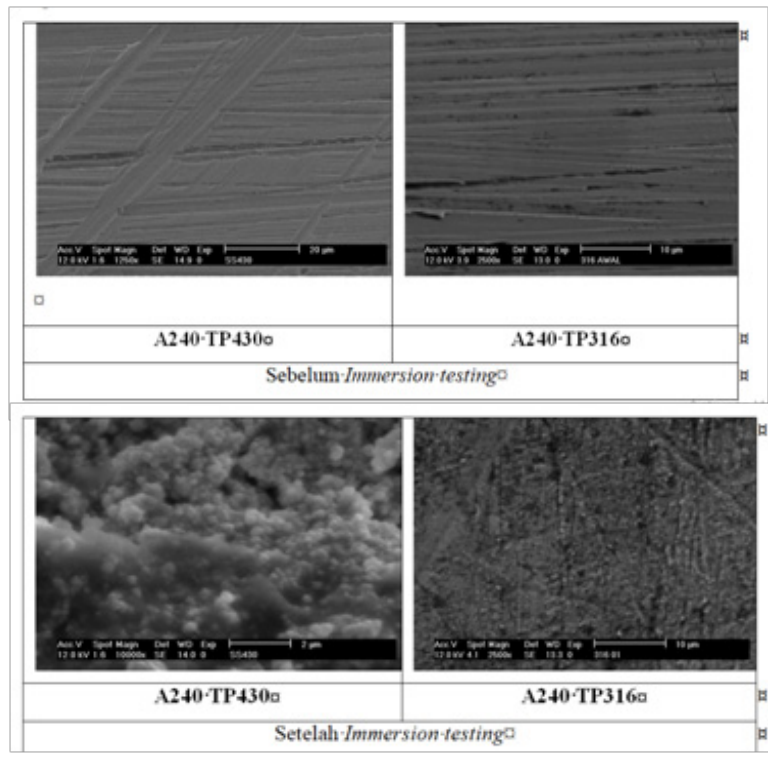

Gambar 3.3 SEM sebelum dan sesudah Immersion.

Ketahanan yang lebih baik terhadap korosi pada A240 TP316 dibandingkan dengan A240 TP430 diduga terkait dengan adanya elemen $\mathrm{Cr}$, Ni, dan Mo serta rendahnya kadar karbon dibandingkan A240 TP430

\subsection{Pengaruh TAN dan temperature terhadap ketahanan korosi}

Untuk mengetahui pengaruh parameter nilai TAN terhadap laju korosi, immersion testing dilakukan pada nilai TAN 45,32, 106,45, 118,89 dan 169,19 mg KOH per gr.sampel PFAD, sementara temperatur kerja adalah $230^{\circ} \mathrm{C}$, tekanan kerja 22,6bar dan kadar air 17\% volume. Kurva korelasi antara parameter nilai TAN dengan laju korosi ditunjukan pada gambar berikut.

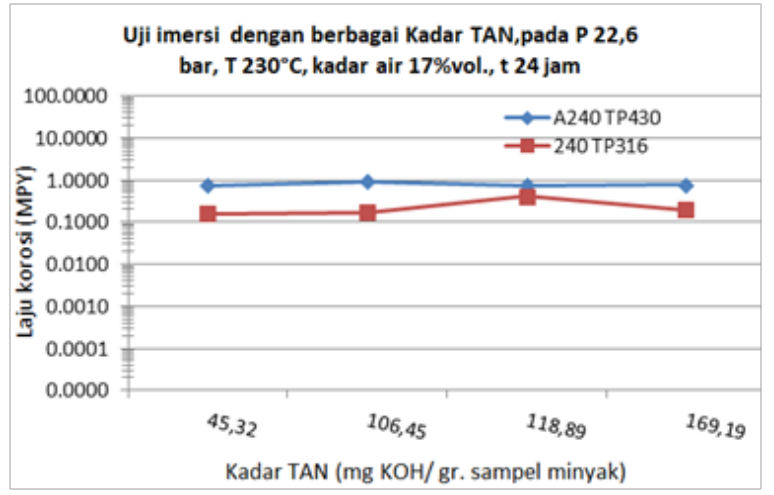

Gambar 3.4 Kurva nilai TAN media, mg KOH/ml sampel vs laju korosi, Mpy

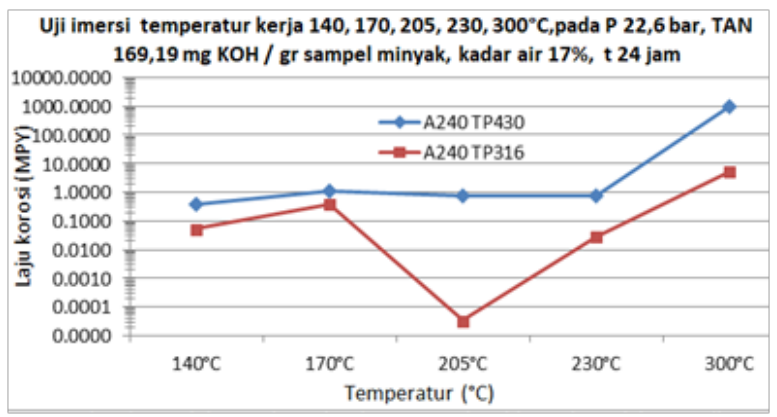

Gambar 3.5 kurva T vs laju korosi

Berdasarkan kurva Gambar 3.4 tersebut, terlihat bahwa ketika immersion testing dilakukandengan nilai - nilai TAN sebagaimana disebut diatas maka nilai TAN tidak berpengaruh secara signifikan terhadap laju korosi A240 TP316 dan A240 TP430. Namun, ketika uji korosi dilakukan pada kondisi temperatur kerja $300^{\circ} \mathrm{C}$, nilai TAN yang semula menunjukan pengaruh terhadap laju korosi, terutama pada A240 TP430.

Hal lain yang bisa dilihat dalam Gambar 3.5 adalah A240 TP316 masih memiliki ketahanan korosi yang baik pada nilai TAN 169,19 mg KOH / ml sampel ketika temperatur dan tekanan kerja $300^{\circ} \mathrm{C}$.

\subsection{Pembahasan}

Ketika immersion testing dilakukan pada nilai TAN 45,32, 106,45, 118,89 dan 169,19 mg $\mathrm{KOH}$ per gr.sampel PFAD, sementara temperatur kerja adalah $230^{\circ} \mathrm{C}$, tekanan kerja 22,6 bar dan kadar air $17 \%$ volume. Kurva korelasi antara parameter nilai TAN dengan laju korosi ditunjukan pada gambar 3.4. Berdasarkan kurva tersebut, terlihat bahwa ketika immersion testing dilakukandengan nilai - nilai TAN sebagaimana disebut diatas maka nilai TAN tidak berpengaruh secara signifikan terhadap laju korosi A240 TP316 dan A240 TP430. Namun, ketika uji korosi dilakukan pada kondisi temperatur kerja $300^{\circ} \mathrm{C}$, nilai TAN yang semula tidak menunjukan laju korosi yang signifikan berubah menunjukan peningkatan laju korosi. Peningkatan laju korosi yang paling signifikan terutama pada A240 TP430. 
Selanjutnya, dari pengamatan visual dengan mikroskop optik dan mikroskop elektron (SEM), material uji A240 TP316 dan A240 TP430 mengalami korosi merata. Jenis korosi yang terjadi kemungkinan besar akan berbeda jika media dalam kondisi mengalir. Foto potongan melintang dan permukaan A240 TP430 menunjukan bahwa material tersebut mengalami proses korosi yang lebih hebat dibandingkan dengan A240 TP316. Daya tahan korosi yang lebih baik pada SS 316 kemungkinan besar didukung elemen paduannya yang lebih kaya akan $\mathrm{Cr}$, Ni, dan Mo serta kadar karbon yang sangat rendah. Oleh karena komposisi yang komplit dan kadar karbon yang lebih rendah, harga 316 kemungkinan akan lebih tinggi dari material uji lain. Walaupun memiliki harga yang tinggi, 316 ini tentu saja dapat dipertimbangkan aplikasinya untuk kondisi kerja yang kritis mengingat penghematan untuk biaya pemeliharaan alat yang dinilai sebanding dengan harga pengadaanya.

\section{KESIMPULAN}

Kesimpulan dari penelitian ini adalah:

- Material mengalami korosi merata.

- Agen korosi berasal dari asam yang termasuk gugusan asam karboksilat.

- Temperatur danTAN berpengaruh terhadap ketahanan korosi material.

- Baja tahan karat austenitic A240 TP 316 memiliki ketahanan korosi yang lebih baik dibandingkan dengan baja karbon, baja krom-moly baja tahan karat feritik ataupun martensitik.

\section{DAFTAR PUSTAKA}

[1] Silva, M.A.V., Ferreira, B.A.G., Marques, L.G.C., Murta, A.L.S., Freitas, M.C.V., \& Marcos A.V.. 2017. Comparative study of NOx emissions of biodiesel-diesel blends from soybean, palm and waste frying oils using methyl and ethyl transesterification routes. Journal of Fuel. pp.144-156.

[2] Sixian, R., et al. 2014. High temperature naphthenic acid corrosion of SA210C and A335 P5. Material and Corrosion, 65(6), pp.
$619-625$.

[3] Ponte, Haroldo A., et al. 2014. TAN influence analysis at the stainless steel corrosion behavior - electrochemical noise technic. Petrobrass.

[4] Bota, Gheorghe, \& Nesic, Srdjan. 2013. Naphthenic acid challenges to iron sulfide scales generated in situ from model oils on mild steel at high temperature. NACE International.

[5] Lu, Thomas. 2012. Challenges in Opportunity Crude Processing. Ecolab

[6] Gabrielsen, Jostein, et al.2011. Hydrotreating of Triglicerides to Make Aviation Biofuels. Biomass. Maryland.

[7] Xue, J., Grift, T.E., \& Hansen A.C.. 2011. Effect of biodiesel on engine performances and emissions. Renew Sustain Energy Rev. pp. 1098-116.

[8] Noiroj,K.,Intarapong,P.,Luengnaruemitchai, A., \&Jai-In, S. 2009. A comparative study of $\mathrm{KOH} / \mathrm{Al} 2 \mathrm{O} 3$ and $\mathrm{KOH} / \mathrm{NaY}$ catalysts for biodiesel production via transesterification from palm oil, . Jurnal Renewable Energy. pp. $1145-1150$

[9] Kanukuntla, Vijaya. 2008. Formation of sulfide scales and their role in naphthenic acid corrosion of steels. Thesis. Ohio University.

[10] Kane, R.D. \& Cayard, M.S.. 2002. A comprehensive study on naphtenic acid corrosion. NACE International.

[11] Petkova, N., dkk. 2002. Establishing the reasons and type of the enhanced corrosion in the crude oil atmospheric distilation unit.

[12] Widyanto, Bambang, dkk. 2012. Penelitian Ketahanan Fasilitas Pengolahan Hydrotreated Bio Diesel (HBD).Bandung : LAPI ITB.

[13] Harvey, David. 2000. Chemistry: Modern Analitycal Chemistry. First Edition. McGraw-Hill.

[14] Zuk, Heinz, David Johnson \& Gregg R McAteer. 2003. Mitigating corrosion from naphthenic acid streams. Ondeo Nalco Energy Services \& Norsk Hydro AS. 